\title{
Perceived Extrinsic Barriers Hinder Community Detection and Management of Mild Cognitive Impairment: A Cross-Sectional Study of General Practitioners in Shanghai, China
}

\section{Yuan Lu}

Yangpu Hospital of Tongji University

Chaojie Liu ( $\nabla$ c.liu@latrobe.edu.au )

La Trobe University

\section{Sally Fawkes}

La Trobe University

\section{Zhaoxin Wang}

Shanghai Jiao Tong University

\section{Dehua Yu}

Shanghai General Practice and Community Health Development Research Center

\section{Research Article}

Keywords: Mild cognitive impairment, Structural equation model, General practitioner, Primary care, Extrinsic barriers

Posted Date: January 27th, 2022

DOl: https://doi.org/10.21203/rs.3.rs-1263375/v1

License: (c) (1) This work is licensed under a Creative Commons Attribution 4.0 International License. Read Full License 


\section{Abstract \\ Background}

General practitioners (GPs) play a critical role in community detection and management of mild cognitive impairment $(\mathrm{MCl})$. Although adequate knowledge is essential, healthcare practice is shaped by many factors, both intrinsic and extrinsic. This study aimed to test the mediating effect of perceived extrinsic barriers on the associations between knowledge, attitudes and intended practice of GPs in community detection and management of $\mathrm{MCl}$.

\section{Methods}

A cross-sectional study was conducted through an online survey of 1253 GPs sampled from 56 community health centres (CHCs) in Shanghai in 2021. Perceived extrinsic barriers were rated on a fivepoint Likert scale for patient engagement, working environment, and system context, respectively. A summed score was generated subsequently for each domain ranging from 0 to 100 , with a higher score indicating higher barriers. The mediating effect of perceived extrinsic barriers (second-order) and the moderation effects of training and past experience on the association between $\mathrm{MCl}$ knowledge and practice scores were tested through structural equation modelling (SEM) with a partial least square (PLS) approach.

\section{Results}

The study participants reported an average barrier score of 65.23 (SD=13.98), 58.34 (SD=16.95) and $60.37(S D=16.99)$ for patient engagement, working environment, and system context, respectively. Although knowledge had both direct and indirect (through attitudes) effects on intended practice, perceived extrinsic barriers negatively mediated $(\beta=-0.012, p=0.025)$ the association between knowledge and practice. Training moderated the effect of knowledge on practice $(\beta=-0.066, p=0.014)$.

\section{Conclusions}

Perceived extrinsic barriers have a detrimental effect on the translation of knowledge into practice for community detection and management of $\mathrm{MCl}$. The effect of training on practice declines when knowledge scores become higher.

\section{Background}

Mild cognitive impairment $(\mathrm{MCl})$ as an intermediate phase between normal cognitive ageing and overt dementia has attracted a great deal of interest in research that aims to reduce the growing burden of dementia (1). In China, the prevalence of $\mathrm{MCl}$ in those aged 55 years or older has reached $17 \%$ (2). $\mathrm{MCl}$ 
was estimated to convert to dementia at a rate of up to $20 \%$ every year if not properly managed (3). The disease management costs would be more than doubled once the cognitive impairment condition progressed into dementia according to the studies conducted in Europe and North America (4).

General practitioners (GPs) play a critical role in community detection and management of $\mathrm{MCl}$. Early community detection and management of $\mathrm{MCl}$ can increase the likelihood of slowing down the fast progression of further cognitive impairment (5). The American Academy of Neurology recommends screening of $\mathrm{MCl}$ in primary care settings so that most of the insidious onset of $\mathrm{MCl}$ in its preclinical asymptomatic phase can be detected (6). The current evidence available regarding effective $\mathrm{MCl}$ management shows that GPs are placed in a unique position to support patients to manage $\mathrm{MCl}(7)$, because non-pharmaceutical measures such as adjustment of the modifiable risk factors (8) (e.g., smoking, diabetes, cerebrovascular disease) and cognitive interventions remain the most cost-effective strategies in $\mathrm{MCl}$ management (9), and all of these measures can be implemented in primary care settings. However, the cognitive problems of a significant number of patients have not been recognised by GPs in their daily practices worldwide (10), even though the majority of GPs acknowledged the value of cognitive impairment assessment in primary care (11). The Aging, Demographics, and Memory Study (ADAMS) in the US showed that in 845 community-based seniors over 70 years, only $8 \%$ had received a memory assessment, compared with $94 \%$ elderly individuals reporting the benefits of early screening and intervention on dementia (12).

A wide range of factors influence the clinical practice of healthcare professionals. A knowledgeable healthcare workforce is key to meeting the changing demands of healthcare services. However, empirical evidence shows that clinical practices of health professionals are not always aligned with their acquired knowledge (13). They can be influenced by the individual motivational predispositions to change, as well as by the organisational, economic, social and political contexts (13). Previous studies show that adherence of medical doctors to practice guidelines is determined by the demands of the individual patient, the beliefs of the medical doctor, the peer culture, the management and organisational climate, health system arrangements, and the broad social environment $(14,15)$. Researchers have attempted to categorise the above-mentioned determinants of practice decisions into various theoretical frameworks. The United Nations Children's Fund (UNICEF, 2019) (16) summarised 25 behavioural theories and models. Although most of the theories have been developed for the purpose of understanding health behaviours of the general public, some have been adopted in studies into the practice behaviours of health professionals. For example, the US CDC Campaign to Prevent Antimicrobial Resistance Team assessed the motivation of hospital physicians to take action to prevent antimicrobial resistance in their patients in line with the health belief model (in terms of perceived susceptibility, severity, benefits, barriers, and selfefficacy) (17). The theory of reasoned action (TRA) was also used in explaining physicians' behaviours based on their individual attitudes (intrinsic motivation), subjective norms (perceived social pressure) and intention to act (18). The theory of planned behaviour (TPB) is another commonly used theory to describe the intention of health professionals to use clinical guidelines, which extends the TRA by adding perceived control over behaviour as a new construct (19). These commonly used behavioural theories examine human behaviours from different angles (20). Nevertheless, they all acknowledge the existence 
of intrinsic and extrinsic drivers despite some bias towards one or the other, which aligns well with the social cognitive theories (13) that emphasise the reciprocal determination in the interaction between people and their environments.

Both intrinsic and extrinsic drivers have been deemed important to incentivise GPs to adopt and adhere to practice guidelines in $\mathrm{MCl}$ detection and management $(7,20)$. There exist variations in the individual (intrinsic) attitudes of GPs toward community detection and management of $\mathrm{MCl}(11,21)$. Attitudinal barriers are particularly detrimental to preventive interventions such as the screening of $\mathrm{MCl}$ (22). Apart from provider-related intrinsic barriers such as a lack of knowledge and confidence, a recent systematic review of 16 studies identified patient-related barriers and system-related barriers that can jeopadise the efforts of primary care physicians to provide optimal dementia care (23). For example, patients may be reluctant to acknowledge cognitive decline and not willing to adhere to management plans; the health system may not dedicate enough resources and managers may not actually render adequate support. There is stigma attached to dementia in the society. Ageism and financial constraints are often blamed for jeopardising the rapid appraisal and management of cognitive disorders in primary care according to another systematic review of 11 studies (24). However, there is a dearth of literature comprehensively assessing the effects of both intrinsic and extrinsic barriers on community detection and management of $\mathrm{MCl}$, in particular in low- and middle-income countries.

This study aimed to address the gap in the literature by testing the mediation role of perceived extrinsic barriers on the associations between knowledge, attitudes and intended practice of GPs in community detection and management of $\mathrm{MCl}$. Findings of the study will also provide evidence in support of the novel development of community-based intervention programs on $\mathrm{MCl}$ in China.

\section{Methods}

\section{Study settings}

This study was conducted in Shanghai, China. Shanghai ranks fourth in population aging in China, with over $16.28 \%$ of its residents exceeding the age of 65 years (25). As one of the earliest cities in China to transition to an aging society, Shanghai is the first in line to develop "Friendly Community Programs" for the elderly with cognitive impairment (26) as part of the Healthy China Strategy (27). Healthcare organisations are encouraged to work in partnerships with local community organisations in responding to the challenge of aging, in particular in relation to cognitive impairment.

GPs have been assigned a critical role in the "Friendly Community Programs". They are supposed to perform $\mathrm{MCl}$ screening and risk assessment, initiate $\mathrm{MCl}$ diagnosis, conduct community interventions, coordinate with other care providers, and educate the public (28). Over the past few decades, China has attempted to revitalise its primary care system through the development of community health services. GPs, as a new medical specialist stream, serve as a backbone in China's community health services (29). In Shanghai, 246 community health centres ( $\mathrm{CHCs}$ ) have been established with an intention to meet the 
essential healthcare needs of all of its residents. About 10,000 GPs (4.12 Per capita) were employed by these CHCs in 2019 (25). To improve the training of qualified GPs, the National Health Commission promulgated a plan to standardise medical training under a new " $5+3$ " framework since 2012 (30), with five years of undergraduate study followed by three years of standardised residency training. However, training programs targeting the screening and interventions of cognitive disorders are limited.

$\mathrm{CHCs}$ receive funding from the local health department that supports infrastructure and population-based services (essential public health services) (31). Individual-based medical care is usually covered by the social health insurance schemes. However, patients are also charged a fee for their individual medical care, albeit at a lower rate compared with their hospital counterparts (32). Currently, the $\mathrm{MCl}$ detection and management services are partly funded through the essential public health services and partly through patients and their health insurance programs. Unfortunately, at this stage there is no additional funding coming through the "Friendly Community Programs" to support the new $\mathrm{MCl}$ management initiative in CHCs.

\section{Hypothesis}

The Knowledge-Attitudes-Practices (KAP) model is arguably the most commonly used theoretical framework in examining the behaviours of health professionals. However, it has been criticised for the lack of considerations of extrinsic factors (33). Empirical evidence shows that human behaviours are not always aligned with individuals' knowledge (13). The choice of actions of health professionals is also shaped by regulations, policies, rules, and pressures from consumers (34). The importance of the influence from the organisational environment, in which a health practitioner works, has been increasingly recognised (35). In this study, we tested the effects of several factors on the K-A-P pathway (Figure 1).

\section{Hypothesis one: perceived extrinsic barriers mediate the effect of knowledge on practice}

We categorised extrinsic barriers into three domains in line with the Chronic Care Model (CCM) (36): patient engagement, working environment and system context. The CCM aims to foster improvements in the care for patients with chronic illnesses by emphasising the importance of prepared, proactive practice teams, well-informed and motivated patients, as well as a system platform that enables effective interactions between the two. The Cochrane Collaboration researchers concluded that high-quality chronic illness care is characterised by a productive interaction between the practice team and its patients (37). Patients need correct and relevant information and confidence to engage in their own care, while the practice team requires time and resources to act. A supportive system fosters an appropriate climate to empower their employees to perform well. Barriers arising from these extrinsic factors can jeopardise the practice efforts of GPs in community detection and management of $\mathrm{MCl}$. 


\section{Hypothesis two: $\mathrm{MCl}$ training moderates the effect of knowledge on practice}

Training has been considered as one of the most important measures to initiate a new medical intervention program. A cohort study in the USA over a two-year period found that training support was effective in improving the confidence of primary care workers in dementia care and their competency in using the cognitive screening tools (38). Continuing education was also found to be beneficial for improving $\mathrm{MCl}$ detection in primary care in a study in Hungary (39).

\section{Hypothesis three: past experience moderates the association between knowledge and perceived extrinsic barriers}

Past experience influences the level of felt easiness of clinicians in making clinical decisions (18). It is also associated with knowledge acquirement. A cross-sectional study of 197 family physicians in Israel found that those who made $\mathrm{MCl}$ diagnoses over the previous six months reported higher levels of $\mathrm{MCl}$ knowledge than those who had not (40). A knowledgeable health practitioner is more likely to be able to identify the existing extrinsic barriers (41). Therefore, it is reasonable to assume that past experience may have a direct effect on perceived extrinsic barriers, and, in turn, may moderate the association between knowledge and perceived extrinsic barriers.

\section{Survey Instruments}

A questionnaire was developed through a thorough examination of the existing tools in relation to the testing constructs $(39,42,43)$. This was followed by focus groups interviews with $32 \mathrm{MCl}$ patients and their caregivers, $42 \mathrm{GPs}$, and $18 \mathrm{CHC}$ managers in order to adapt the tools to the specific context of China. Two rounds of Delphi consultations with 23 experts were conducted to achieve consensus on the measurements.

The questionnaire contained three sections. Section one measured the characteristics of the study participants, including their training and working experience in relation to $\mathrm{MCl}$.

Section two measured the MCl-related KAP of the study participants. The KAP measurements adopted a formative structure, covering all essential elements required in community detection and management of $\mathrm{MCl}$, including perceived intrinsic barriers embedded in the measurement of attitudes (in terms of perceived seriousness of the problem and benefits and self-efficacy in $\mathrm{MCl}$ management). A summed score was calculated for knowledge, attitudes, and practice, respectively, and transformed into a standardised score ranging from 0 to 100 , with a higher score indicating a trend in favour of community detection and management of $\mathrm{MCl}$. The KAP scales were validated using the four criteria recommended by Diamantopoulos and Winklhofer (44) including content specification, indicator specification, indicator collinearity, and external validity, which were reported in our previous study (45). 
Section three measured perceived extrinsic barriers reflected on three domains: patient engagement, working environment, and system context. The measurement of perceived barriers in patient engagement followed the conceptual framework developed by Davis et al through a comprehensive literature review (46). It contained 14 items, including person-related (8 items), illness-related ( 2 items), healthcare professional-related ( 2 items), health care setting-related ( 1 items), and task-related ( 1 item) barriers. Perceived barriers in working environment were measured in line with the "building blocks" suggested by the World Health Organization (WHO) (47), including leadership/governance (2 items), financing (1 item), workforce (4 items), information systems ( 1 item), and service delivery (4 items). Perceived barriers in system context reflects the broad system and societal environments in which a health care organisation operates. The measurement was informed by the framework of structural domains for primary care developed by the Lamont Primary Health Care Research Centre in Canada (48). It contained 7 items, including 2 items reflecting the financial and policy support from the government and the health system, respectively, and 3 items measuring acceptance of $\mathrm{MCl}$ detection and management from the broad society and the public media.

Study participants were asked to rate each item on a five-point Likert scale, ranging from 1 (strongly disagree) to 5 (strongly agree). A summed score was calculated for each domain and then transformed into a standardised score ranging from 0 to 100. A higher score indicates a higher level of perceived extrinsic barriers.

\section{Study participants and data collection}

Data were collected from $56 \mathrm{CHCs}$ out of $246 \mathrm{CHCs}$ across all 16 districts in Shanghai during the period from 13 April to 9 May in 2021. A stratified cluster sampling strategy was applied to recruit participants in proportion with the district distribution of the $\mathrm{CHCs}$. Eligible participants were registered GPs in the $\mathrm{CHCs}$ who had direct contacts with patients.

Permission from the senior managers of the targeted CHCs was sought through emails before a survey invitation was dispatched to all of their eligible GPs. Study respondents were invited to provide implied informed consent before proceeding to the survey. The survey was anonymous and respondents could withdraw at any time.

The survey took around 15 minutes to complete via the online platform RedCAP (49). In total, 1789 of the invited participants accessed the survey platform, with 1740 being recorded with a submission. Of the returned questionnaires, 1253 contained no missing items and were included in data analyses. This represented an effective response rate of $70.04 \%$. The sample size was large enough for the purpose of PLS-SEM modelling, which is known for its advantage of handling large numbers of items with a relatively small sample size (50).

Ethical clearance to conduct the study was obtained from the Research and Ethics Committee of La Trobe University in Melbourne, Australia (HEC20143) and Yangpu Hospital in Shanghai, China (LL-2019$\mathrm{SCl}-004)$. 


\section{Statistical Analysis}

Perceived extrinsic barriers were described through frequency distribution of items and using summed scores (Mean \pm Standard Deviation) of the three domains: patient engagement, working environment, and system context. Pearson correlation analyses were performed to test the relationships between the $\mathrm{MCl}$ related KAP scores and the three domains of perceived extrinsic barriers.

Structural equation modeling (SEM) was established to determine the mediation effect of perceived extrinsic barriers and the moderation effects of training and past experience on the association between knowledge and intended practice of GPs in community detection and management of $\mathrm{MCl}$. In the SEM, the three domains of extrinsic barriers formed a second-order construct. Intended practice was also deemed a second-order construct, comprising three domains: alerting, confirming, and managing.

A partial least squares (PLS) approach was selected in the SEM because of the complex exploratory nature of the model and the inclusion of both reflective and formative constructs. PLS-SEM adopts a nonparametric method, which does not have restrictive requirements on the distribution of data (50). In this study, two successive model assessments were performed: measurement tests followed by structural tests. The reliability of the scales measuring the three domains of extrinsic barriers was assessed using Cronbach's alpha ( $>0.7)$, composite reliability ( $\mathrm{CR}>0.7)$, and $\rho \mathrm{A}(>0.7)$. Items with a loading lower than 0.7 were retained if removal of the item would not increase composite reliability (50). The convergent validity of the scales was assessed using average variance extracted (AVE $\geq 0.50)(50)$. The Heterotrait-monotrait criterion ( $\mathrm{HTMT}<0.90)$ was used to establish discriminant validity $(51)$. The structural tests were performed through two steps after confirmation of the reliability and validity of the measurement scales. A "PLS Algorithm" was run first to generate factor scores for the latent variables. The factor scores were then used in calculating the path coefficients with consistent bootstrapping (5000 bootstrap re-samples) in order to avoid artificially correlated residuals resulting from the repeated use of indicators in the model (52).

Data analyses were performed using SmartPLS 3.3.3 (53) and IBM SPSS 27.0. All analyses were twotailed, and a $p \leq 0.05$ was considered statistically significant.

\section{Results}

\section{Sociodemographic characteristics of respondents}

The vast majority (93.4\%) of respondents worked in the department of general practice. Nearly $80 \%$ were in the age range of $30-49$ years and $70 \%$ were female. Only $4.0 \%$ did not have a bachelor degree. About $36.6 \%$ had 15 or more years of working experience. Over two thirds of respondents had a middle professional title. Only $14.8 \%$ had been involved in $\mathrm{MCl}$ detection and management in the past. Less than $30 \%$ reported having received $\mathrm{MCl}$ training, but only $4.2 \%$ were awarded with a qualification for $\mathrm{MCl}$ screening. 


\section{Perceived Extrinsic Barriers}

The scales measuring perceived extrinsic barriers showed satisfactory reliability, with Cronbach's alpha, rho-A, and composite reliability coefficients all exceeding the threshold of 0.7 (Additional File 1). All of the measurement items were retained. Although the loading of one item fell below 0.7 , removal of the item would not increase the composite reliability of its respective domain. The convergent and discriminatory validity of the measurement scales were confirmed by the AVE (Additional File 1) and the HTMT (Additional File 2) criteria, respectively.

On average, the study participants reported a barrier score (Mean \pm Standard Deviation) of $65.23 \pm 13.98$, $58.34 \pm 16.95$ and $60.37 \pm 16.99$ for patient engagement, working environment, and system context, respectively. More respondents appear to agree with barriers in patient engagement. In terms of patientengagement barriers, stigma was the most frequently (68.9\%) reported one, followed by a lack of confidence in GPs (68.7\%). Time constraints (53.5\%) and a lack of effective tools (53.5\%) and financial incentives (48.5\%) were the most frequently reported barriers in working environment. More than half of the respondents considered the absence of $\mathrm{MCl}$ management in the essential public health services package and the primary care payment scheme as a major system barrier (Table 1). 
Table 1

Perceived extrinsic barriers reported by study participants

\section{Perceived extrinsic barriers}

\section{Patient Engagement}

1. Most people would take $\mathrm{MCl}$ as normal ageing.

2. Most people don't believe there exist effective methods to treat $\mathrm{MCl}$.

3. Most people believe the diagnosis of $\mathrm{MCl}$ would lead to stigma.

4. Patients prefer to go to a specialist hospital or tertiary hospital if they have cognitive disorder.

5. Most people don`t have confidence in GPs to detect and manage $\mathrm{MCl}$.

6. Only when cognition was seriously affected would people go to see a doctor.

7. People would consider $\mathrm{MCl}$ screening tests are too lengthy.

8. Most people would not detect or manage $\mathrm{MCl}$ with money out of pocket.

9. Most family would not support $\mathrm{MCl}$ detection and management.

10. Most family feel helpless to urge suspected patients to take $\mathrm{MCl}$ detection and management.

11. The less valued by the family, the less likely people would participate in $\mathrm{MCl}$ detection and management.

12. People' negative attitudes towards life would discourage them to engage in $\mathrm{MCl}$ detection and management.

13. People would not pay much attention to $\mathrm{MCl}$ when suffered from too many chronic diseases.

14. Good relationship with GPs will help patients engage in $\mathrm{MCl}$ detection and management.
Number (percentage) of respondents
Strongly disagree Strongly agree Unsure Disagree agree

$4.4 \%$

$55.1 \%$

$34.5 \%$

$5.0 \%$

$1.0 \%$

$4.2 \%$

$46.4 \%$

$40.7 \%$

$7.5 \%$

$1.1 \%$

$10.9 \%$

$58.0 \%$

$27.6 \%$

$2.5 \%$

$1.0 \%$

$7.2 \%$

$53.6 \%$

$34.6 \%$

$3.8 \%$

$0.7 \%$
$8.8 \%$

$6.6 \%$

$51.6 \%$

$59.9 \%$

$27.7 \%$

$2.9 \%$

$0.8 \%$

$8.5 \%$

$53.7 \%$

$34.0 \%$

$2.9 \%$

$0.9 \%$

$4.7 \%$

$43.1 \%$

$44.3 \%$

$7.1 \%$

$0.8 \%$

$4.9 \%$

$49.6 \%$

$41.5 \%$

$3.2 \%$

$0.7 \%$

$4.9 \%$

$49.8 \%$

$39.7 \%$

$4.9 \%$

$0.8 \%$

$5.2 \%$

$55.0 \%$

$35.5 \%$

$3.4 \%$

$0.9 \%$

$6.8 \%$

$56.5 \%$

$32.4 \%$

$3.6 \%$

$0.7 \%$

$59.9 \%$

$29.4 \%$

$3.9 \%$

$1.0 \%$

$5.8 \%$

$29.4 \%$

$59.9 \%$

$29.4 \%$

$3.9 \%$

$1.0 \%$

$5.8 \%$

59

.
Strongly Agree Unsure Disagree agree




\section{Perceived extrinsic barriers}

1. There exist no evidence-based guidelines designed to facilitate $\mathrm{MCl}$ detection and management in our community health centre.

2. There exist no economic reimbursement in our community health centre to encourage $\mathrm{MCl}$ detection and management.

3. I don't have enough disposable time to detect and manage $\mathrm{MCl}$.

4. The institutional routine policies in our community health centre did not include the practice of detecting and managing $\mathrm{MCl}$.

5. There exists no referral pathway to encourage $\mathrm{MCl}$ detection and management in our community health centre.

6. There exists no supportive team in our community health centre to help GPs to detect and manage $\mathrm{MCl}$.

7. Our community health center provides no specific training on $\mathrm{MCl}$ detection and management.

8. The clinic electronic system health centre is lack of function for improving $\mathrm{MCl}$ detection and management.

9. There is a lack of essential tools for detecting and managing $\mathrm{MCl}$ in our community health centre.

10. There are not enough facilities and space in our community health centre to detect or manage $\mathrm{MCl}$ in our community.

11. There are seriously lack of human resources in our community health centre.

12. Managers in our community health centre put less emphasis on $\mathrm{MCl}$ detection and management.

\section{System Context}

1. The government put less investment on $\mathrm{MCl}$ detection and management.

2. $\mathrm{MCl}$ detection and management has not been accepted by the whole society.

\section{Number (percentage) of respondents}

$\begin{array}{lllll}5.3 \% & 36.6 \% & 45.1 \% & 10.9 \% & 2.1 \%\end{array}$

$\begin{array}{lllll}7.2 \% & 41.3 \% & 42.2 \% & 7.3 \% & 2.0 \%\end{array}$

$\begin{array}{lllll}8.7 \% & 44.8 \% & 37.1 \% & 7.9 \% & 1.5 \%\end{array}$

$\begin{array}{lllll}6.5 \% & 41.2 \% & 41.9 \% & 8.7 \% & 1.8 \%\end{array}$

$5.6 \%$

$32.5 \%$

$42.9 \% \quad 16.3 \%$

$2.7 \%$

$5.8 \%$

$35.6 \%$

$44.5 \%$

$12.1 \%$

$1.9 \%$

$5.2 \%$

$33.4 \%$

$43.5 \%$

$16.1 \%$

$1.8 \%$

$6.0 \%$

$40.4 \%$

$41.8 \%$

$9.9 \%$

$1.9 \%$

$6.8 \%$

$42.2 \% \quad 41.3 \%$

$8.1 \%$

$1.5 \%$

$7.0 \%$

$41.5 \%$

$41.3 \%$

$8.4 \%$

$1.8 \%$

$6.4 \%$

$28.7 \%$

$43.5 \%$

$17.8 \%$

$3.7 \%$

$4.6 \%$

$23.8 \%$

$52.2 \%$

$16.3 \%$

$3.1 \%$

Strongly agree

Agree Unsure Disagree

$7.6 \%$

$36.7 \%$

$50.0 \%$

3.5

2.2

Strongly disagree
$4.7 \%$
$29.4 \%$
$45.6 \%$
16.4
4.0 


\section{Perceived extrinsic barriers}

3. The public media focus less on the topic of $\mathrm{MCl}$.

4. There exist less publication of $\mathrm{MCl}$ detection and management from the public media.

5. The primary health care system does not cover payments from $\mathrm{MCl}$ detection and management.

6. The basic package of public health provides no definite stipulation on $\mathrm{MCl}$ detection and management.

7. The governments' legislative regulations did not clarify specific roles of different professions to detect and manage $\mathrm{MCl}$.

Number (percentage) of respondents

$\begin{array}{lllll}5.7 \% & 36.6 \% & 44.5 & 11.2 & 2.2\end{array}$

$6.1 \%$

$44.4 \% \quad 41.1$

6.5

2.0

$10.4 \%$

$43.3 \%$

39.9

4.5

1.9

$8.1 \%$

$42.9 \%$

41.6

5.0

2.3

Insert Table 1 here.

\section{Correlations Between Kap Scores And Perceived Extrinsic Barriers}

The three domains of perceived barriers were positively correlated each other $(p<0.001)$. Perceived barriers in patient engagement were negatively associated with $\mathrm{MCl}$-related knowledge, attitudes and intended practice of GPs $(p<0.001)$. Perceived barriers in system context were negatively associated with $\mathrm{MCl}-$-related knowledge and attitudes $(p<0.001)$, compared with a marginal positive correlation between perceived barriers in working environment and intended behaviours $(p=0.039)$ (Table 2). 
Table 2

Correlation matrix of the relationship among the latent variables

\begin{tabular}{|llllll|}
\hline & $\mathbf{1}$ & $\mathbf{2}$ & $\mathbf{3}$ & $\mathbf{4}$ & $\mathbf{5}$ \\
\hline 1. Perceived system context & 1 & & & & \\
\hline 2. Perceived working environment & $0.620^{\star \star}$ & 1 & & & \\
\hline 3. Perceived Patient engagement & $0.467^{* \star}$ & $0.450^{* \star}$ & 1 & & \\
\hline 4. Intended behaviour & -0.002 & $0.058^{*}$ & $-0.116^{* \star}$ & 1 & \\
\hline 5. Attitudes & $-0.104^{\star \star}$ & -0.006 & $-0.312^{* \star}$ & $0.211^{* \star}$ & 1 \\
\hline 6. knowledge & $-0.075^{\star \star}$ & -0.008 & $-0.180^{\star *}$ & $0.212^{* \star}$ & $0.248^{\star \star}$ \\
\hline Note: ${ }^{*} p=0.039^{* \star} p<0.001$ & & & & & \\
\hline
\end{tabular}

\section{Structural equation model}

Knowledge was associated with intended practice, with the direct effect contributing to $68.2 \%$ of the total effect. The indirect effects of knowledge on intended practice via attitudes (84.6\%) and perceived extrinsic barriers (-15.4\%) were both statistically significant (Additional File 3).

While attitudes mediated the effect of knowledge on intended practice in a positive manner, the mediating effect of perceived extrinsic barriers was negative (Figure 2). High $\mathrm{MCl}$ knowledge was associated with higher levels of perceived extrinsic barriers $(\beta=0.131, p<0.001)$; whereas, higher perceived extrinsic barriers led to lower intention of adherence to practice guidelines $(\beta=-0.091, p=0.012)$.

Training was associated with higher levels of practice compliance $(\beta=0.132, p<0.001)$. It also moderated the association between knowledge and intended practice $(\beta=-0.066, p=0.017)$ : the effect of training was less powerful when GPs had a higher level of knowledge (Figure 3 ).

Past experience had no significant relationship with perceived extrinsic barriers $(\beta=-0.061, p=0.084)$, nor did it moderate the association between knowledge and perceived extrinsic barriers $(\beta=0.027, p=0.400)$.

\section{Discussion}

This study assessed the perceived extrinsic barriers and their mediating effect on the association between knowledge and intended practice of GPs in community $\mathrm{MCl}$ detection and management. Our study revealed that social stigma and a lack of confidence in GPs are major barriers of patient engagement as perceived by the GP respondents, while resource constraints and a lack of policy, financial and policy support are major working environment and system barriers. The perceived extrinsic barriers have a negative mediating effect on the association between knowledge and intended behaviour, 
hence, hypothesis one is supported. Training has a positive moderating effect on the association between knowledge and intended behaviour, and the effect is less powerful when GPs have a higher level of knowledge, hence, hypothesis two is supported. However, past experience did not show a significant effect on perceived extrinsic barriers, hence, hypothesis three is not supported.

This study indicated that both intrinsic drivers (such as knowledge and attitudes of physicians) and extrinsic drivers (patient engagement, working environment, and system context) have shaped the behaviour of primary care physicians in detecting and managing $\mathrm{MCl}$. These results are consistent with the findings reported in a recent systematic review (23), which categorised barriers of dementia care into patient, provider, and system related. The influence of system context on health practice has been widely acknowledged in health policy documents $(54,55)$. The organisational factors have been identified as influencing the motivation of healthcare providers from both the perspectives of financial and nonfinancial incentives (35). The average barrier score for patient engagement was found to be 65.23 out of a maximal of 100 in this study, which is the highest among the three barrier domains. A cross-sectional survey of 703 GPs in the Netherlands (ref) indicated that the most perceived barriers to implementing clinical guidelines came from external factors, especially patient preferences, needs and abilities (56). However, findings on improving physician guideline adherence behaviour may not be generalisable, since barriers in one setting may not be present in another.

Our SEM results showed that perceived extrinsic barriers had a negative mediating impact $(\beta=-0.012$, $p=0.025$ ) on the association between knowledge and intended behaviour, accounting for $15.4 \%$ of all indirect effects. A partial mediating effect was confirmed, which suggests that the K-A-P pathway remains to be a major pathway for translating knowledge into practice, and perceived extrinsic barriers have a weak but non-negligible effect on the intended behaviours of GPs in $\mathrm{MCl}$ detection and management. Therefore, there is no doubt that the intention of GPs to detect and manage $\mathrm{MCl}$ can be compromised when they perceive high levels of extrinsic barriers. Accordingly, it could be understandable why GPs rarely detected $\mathrm{MCl}$ in practice (10) even though the majority of primary care physicians acknowledged the value of assessing cognitive impairment in primary care (11).

The association between higher knowledge and higher perceived extrinsic barriers is concerning. It is likely that the GPs with a high level of MCl-related knowledge are more likely to notice potential extrinsic barriers in their practice compared with those with a low level of knowledge. Those knowledgeable physicians may perceive more challenges when the process of implementing approaches impacts their routines and workflow, and requires them to work in new ways. Similarly, a systematic review (57) found that workload and time constraints are dominant barriers to implementing evidence-based dementia care.

The moderation analyses showed that training can potentially improve compliance to practice guidelines. However, the effect of training is less powerful when GPs have already had a higher level of knowledge. It is important to note that knowledge is often acquired through training, but high knowledge is also associated with high perceived barriers. A systematic review of six studies (58) concludes that education alone would not increase adherence of primary care to dementia care guidelines. However, a targeted 
physician practice-based educational intervention along with community services support is more effective for improving the dementia care competency of clinicians according to a cohort study (36).

In this study, we did not find a significant moderation effect of past experience on the association between knowledge and perceived extrinsic barriers. It may be, at least partly, due to the fact that only $14.8 \%$ of the GP respondents reported experience of $\mathrm{MCl}$ detection and management. Community-based $\mathrm{MCl}$ management is still in its initial development stage in China. Some GPs may have obtained the experience through research or experimental studies. However, implementation or incorporation of the services into routine practice is a different matter. The additional resources available to a research project are likely to disappear. The patients receiving services may become more diversified. The widespread participation of GPs in the new initiative would require some additional incentives. Unfortunately, those who are prepared to practice are more likely to be aware of the barriers in working environment according to the findings of this study. This result is consistent with the results of a qualitive study that explored a "disconnect" between perceptions of GPs and other providers regarding the need for implementation of a chronic disease prevention program in primary care settings. GPs are likely to be more concerned about the lack of a supportive environment than their colleagues (59).

The findings of this study have some implications for policy and management as well as educational activities. Extrinsic barriers in relation to patient engagement, working environment, and system context should be addressed to provide support to GPs in community detection and management of $\mathrm{MCl}$. According to Herzberg's motivation theory (60), those extrinsic barriers are deemed as hygiene factors which can result in staff dissatisfaction if not addressed properly, even though they do not in themselves motivate employees. They may even deter the efforts of some intrinsically motivated GPs. Training remains critical given that the overall knowledge level of GPs in $\mathrm{MCl}$ detection and management is low. Training is particularly powerful when knowledge is low. Meanwhile, however, GPs need to be equipped with skills to adequately cope with the challenging environment. This should include, but not be limited to, more proactive engagement in patient and public education campaigns and advocacy for increasing policy and management support to community detection and management of $\mathrm{MCl}(61)$.

\section{Strengths and limitations}

The SEM-PLS method was adopted to explore the complex exploratory structural equation model with both formative and reflective measures. This study tested the mediating effect of perceived extrinsic barriers and the moderation effects of training and past experience on the association between $\mathrm{MCl}$ knowledge and intended practice in a large sample of GPs. The findings have both policy/management and training implications for developing the programs in relation to community detection and management of $\mathrm{MCl}$ in response to the challenges of an aging society.

Like any other study, this study also has some limitations. Firstly, although this survey included a large sample size, it did not represent the entire GP workforce. Attempts to generalise findings of this study should be undertaken cautiously. Secondly, the concept of perceived barriers measured in this study is not equivalent to the objective existence of extrinsic barriers. Data were collected through self-reporting, 
which is subject to reporting bias. However, perceived extrinsic barriers bear a more direct connection with behavioural intentions (13). Finally, we took intended behaviour to be an outcome measurement, since there exist limited actual $\mathrm{MCl}$ detection and management activities including those originating from research and experimental projects. However, intended behaviour has been regarded as the most immediate predictor of actual behaviour, even though there exists an intention-behaviour gap (62). A meta-analysis of 10 meta-analyses concluded that intention accounts for almost one-third of the variance in behaviour (63).

\section{Conclusions}

Perceived extrinsic barriers jeopardise the translation of $\mathrm{MCl}$ knowledge into intended actions that comply with practice guidelines in GPs in Shanghai. Although intrinsic drivers account for the majority of indirect effects between knowledge and intended practice, perceived extrinsic barriers negatively mediate the association between knowledge and practice. Training can improve practice; however, its effect is more powerful when knowledge level is low. Training alone is not enough as increased knowledge can be associated with higher perceived extrinsic barriers. Extrinsic barriers need to be addressed to support the efforts of GPs in community detection and management of $\mathrm{MCl}$. Training should be prioritised to those with lower $\mathrm{MCl}$ knowledge, and enhance the skills of GPs to adequately cope with the challenging environment.

\section{Abbreviations}

GPS

General practitioners

$\mathrm{MCl}$

mild cognitive impairment

KAP

knowledge, attitudes and practice

CHCs

community health centres

$\mathrm{CCM}$

the Chronic Care Model

\section{Declarations}

\section{Ethical approval and consent to participants}

This study was approved by the Human Ethics Committee of La Trobe University (HEC20125) and the Medical Ethics Committee of Yangpu Hospital, Shanghai, China (LL-2019-SCI-004). Implied informed consent was obtained from each participant prior to the survey. All methods were carried out in accordance with relevant guidelines and regulations. 


\section{Consent to publication}

Not applicable.

\section{Data availability}

The datasets generated and analysed during the current study are not publicly available due to policies from the ethic committee, but are available from the corresponding author $C L$ on reasonable request.

\section{Funding}

The project was supported by the Australian Government Research Training Program Fees Offset (RTP Fees Offset) and the La Trobe University Full Fee Research Scholarship (LTUFFRS). This work was also supported by the fund from Shanghai Municipal Health Commission, Shanghai, China (201940495). The funding bodies did not have any involvement in the design, execution and writing up of the study.

\section{Author Contribution}

YL contributed to the conceptualisation of the study, analyses and interpretation of the data, and was the primary person responsible for drafting the manuscript. CL contributed to the conceptualisation of the study, guided data analyses and interpretation of the data, critically revised the manuscript. SF critically revised the manuscript. DHY contributed to the data collection and facilitated the survey. ZXW supported data collection. All authors made critical contributions to the academic contents and approved the final manuscript.

\section{Conflict of interest}

The authors declare no competing interests.

\section{Acknowledgement}

The research underpinning this publication was undertaken while completing a $\mathrm{PhD}$ at La Trobe University, Melbourne, Australia. The authors are grateful to the participants involved in this research.

\section{References}

1. Tong T, Thokala P, McMillan B, Ghosh R, Brazier J. Cost effectiveness of using cognitive screening tests for detecting dementia and mild cognitive impairment in primary care. Int J Geriatr Psych. 2017;32(12):1392-400.

2. Lu Y, Liu C, Yu D, Fawkes S, Ma J, Zhang M, et al. Prevalence of mild cognitive impairment in community-dwelling Chinese populations aged over 55 years: a meta-analysis and systematic review. BMC Geriatr. 2021;21(1):10. 
3. Langa KM, Levine DA. The diagnosis and management of mild cognitive impairment: A clinical review. JAMA. 2014;312(23):2551-61.

4. Quentin W, Riedel-Heller S, Luppa M, Rudolph A, König HH. Cost-of-illness studies of dementia: a systematic review focusing on stage dependency of costs. Acta Psychiat Scand. 2010;121(4):24359.

5. Ngandu T, Lehtisalo J, Solomon A, Levälahti E, Ahtiluoto S, Antikainen R, et al. A 2 year multidomain intervention of diet, exercise, cognitive training, and vascular risk monitoring versus control to prevent cognitive decline in at-risk elderly people (FINGER): a randomised controlled trial. The Lancet. 2015; 385(9984):2255-63.

6. Petersen RC, Lopez O, Armstrong MJ, Getchius TSD, Ganguli M, Gloss D, et al. Practice guideline update summary: Mild cognitive impairment: Report of the Guideline Development, Dissemination, and Implementation Subcommittee of the American Academy of Neurology. Neurology. 2018;90(3):126-35.

7. Ambigga D, Suthahar A, Ramli AR, Ng KK, Radziah A, Marymol K. Diagnosis and management of mild cognitive impairment in the community: What is the role of primary care physician? Malaysian Family Physician. 2011;6(2-3):74-8.

8. Jia L, Du Y, Chu L, Zhang Z, Li F, Lyu D, et al. Prevalence, risk factors, and management of dementia and mild cognitive impairment in adults aged 60 years or older in China: a cross-sectional study. The Lancet Public Health. 2020;5(12):e661-e71.

9. Sherman DS, Mauser J, Nuno M, D S. The Efficacy of Cognitive Intervention in Mild Cognitive Impairment (MCl): A Meta-Analysis of Outcomes on Neuropsychological Measures. Neuropsychol Rev. 2017;27(4):440-84.

10. Kaduszkiewicz H, Zimmermann T, Van den Bussche H, Bachmann C, Wiese B, Bickel H, et al. Do general practitioners recognize mild cognitive impairment in their patients? J Nutr Health Aging. 2010;14(8):697-702.

11. Rodda J, Gandhi SD, Mukadam N, Walker Z. Attitudes of UK psychiatrists to the diagnosis of $\mathrm{MCl}$ in clinical practice. Int Psychogeriatr. 2013;25(2):286-91.

12. Kotagal V, Langa KM, Plassman BL, Fisher GG, Giordani BJ, Wallace RB, et al. Factors associated with cognitive evaluations in the United States. Neurology. 2015;84(1):64-71.

13. Godin G, Belanger-Gravel A, Eccles M, Grimshaw J. Healthcare professionals' intentions and behaviours: a systematic review of studies based on social cognitive theories. Implement Sci. 2008;3:36.

14. Cabana MD, Rand CS, Powe NR, Wu AW, Wilson MH, Abboud P-AC, et al. Why don't physicians follow clinical practice guidelines?: A framework for improvement. JAMA. 1999;282(15):1458-65.

15. Grol R, Grimshaw J. From best evidence to best practice: effective implementation of change in patients' care. The Lancet. 2003;362(9391):1225-30.

16. Petit V. The Behavioural Drivers Model: A Conceptual Framework for Social and Behaviour Change Programming. UNICEF.2019. 
17. Brinsley KJ, Sinkowitz-Cochran RL, Cardo DM, The CDCCtPART. Assessing motivation for physicians to prevent antimicrobial resistance in hospitalized children using the Health Belief Model as a framework. Am J Infect Control. 2005;33(3):175-81.

18. Fleming ML, Driver L, Sansgiry SS, Abughosh SM, Wanat M, Sawant RV, et al. Physicians' intention to prescribe hydrocodone combination products after rescheduling: A theory of reasoned action approach. Res Social Adm Pharm. 2017;13(3):503-12.

19. Kortteisto T, Kaila M, Komulainen J, Mäntyranta T, Rissanen P. Healthcare professionals' intentions to use clinical guidelines: a survey using the theory of planned behaviour. Implement Sci. 2010;5(1):110.

20. Glanz K, Rimer BK, Viswanath K. Health behavior and health education: theory, research, and practice: John Wiley \& Sons; 2008.

21. Sabbagh MN, Boada M, Borson S, Chilukuri M, Doraiswamy PM, Dubois B, et al. Rationale for Early Diagnosis of Mild Cognitive Impairment $(\mathrm{MCl})$ Supported by Emerging Digital Technologies. JPAD-J prev Alzheim. 2020;7(3):158-64.

22. Davneet Judge, Jenna Roberts, Rezaul Khandker, Baishali Ambegaonkar, Black CM. Physician Perceptions about the Barriers to Prompt Diagnosis of Mild Cognitive Impairment and Alzheimer's Disease. Int of Alzheimer's Dis. 2019;2019:3637954.

23. Mansfield E, Noble N, Sanson-Fisher R, Mazza D, Bryant J. Primary care physicians' perceived barriers to optimal dementia care: A systematic review. The Gerontologist. 2019;59(6):e697-e708.

24. Koch T, lliffe S. Rapid appraisal of barriers to the diagnosis and management of patients with dementia in primary care: a systematic review. BMC Fam Pract. 2010;11:52.

25. Shanghai Statistics Bureau. Shanghai statistical yearbook 2020. Available at: https://www.yearbookchina.com/naviBooklist-n3020013183-1.html; (accessed on 06/5/2021)

26. Shanghai Civil Affairs Bureau. To develop "Friendly Community Programs" for the elderly with cognitive impairment. Available at: https://mzj.sh.gov.cn/MZ_zhuzhan279_0-2-8-15-55231/20201020/871c380077834e93b711974059705902.html; (accessed on 06/5/2021)

27. Yip W, Fu H, Chen AT, Zhai T, Jian W, Xu R, et al. 10 years of health-care reform in China: progress and gaps in Universal Health Coverage. Lancet (London, England). 2019;394:1192-204.

28. Bhattacharyya O, Delu Y, Wong ST, Bowen C. Evolution of primary care in China 1997-2009. Health Policy. 2011;100(2-3):174-80.

29. Li X, Lu J, Hu S, Cheng KK, De Maeseneer J, Meng Q, et al. The primary health-care system in China. The Lancet. 2017;390(10112):2584-94.

30. Tam YH, Leung JYY, Ni MY, Ip DKM, Leung GM. Training sufficient and adequate general practitioners for universal health coverage in China. BMJ. 2018;362:k3128.

31. Yu Y, Sun $X$, Zhuang Y, Dong $X$, Liu H, Jiang $P$, et al. What should the government do regarding health policy-making to develop community health care in Shanghai? Int $\mathrm{J}$ Health Plann Manage. 2011;26(4):379-435. 
32. Chen J, Xu S, Gao J. The Mixed Effect of China's New Health Care Reform on Health Insurance Coverage and the Efficiency of Health Service Utilisation: A Longitudinal Approach. Int J Environ Res Public Health. 2020;17(5).

33. Duan Z, Liu C, Han M, Wang D, Zhang X, Liu C. Understanding consumer behavior patterns in antibiotic usage for upper respiratory tract infections: A study protocol based on the COM-B framework. Res Social Adm Pharm. 2021;17(5):978-85.

34. Braithwaite J, Herkes J, Ludlow K, Testa L, Lamprell G. Association between organisational and workplace cultures, and patient outcomes: systematic review. BMJ open. 2017;7(11):e017708.

35. Afolabi A, Fernando S, Bottiglieri T. The effect of organisational factors in motivating healthcare employees: a systematic review. British Journal of Healthcare Management. 2018;24(12):603-10.

36. Bodenheimer T, Wagner EH, Grumbach K. Improving primary care for patients with chronic illness: the chronic care model, Part 2. JAMA. 2002;288(15):1909-14.

37. Albers B, Shlonsky A, Mildon R. Implementation Science 3.0. 1st ed. 2020. ed: Cham: Springer International Publishing: Imprint: Springer; 2020.

38. Lathren CR, Sloane PD, Hoyle JD, Zimmerman S, Kaufer D. Improving dementia diagnosis and management in primary care: a cohort study of the impact of a training and support program on physician competency, practice patterns, and community linkages. BMC geriatrics. 2013;13(1):1-7.

39. Imre N, Balogh R, Papp E, Kovacs I, Heim S, Karadi K, et al. Knowledge of general practitioners on dementia and mild cognitive impairment: a cross-sectional, questionnaire study from Hungary. Educational Gerontology. 2019;45(8):495-505.

40. Werner P, Heinik J, Kitai E. Familiarity, knowledge, and preferences of family physicians regarding mild cognitive impairment. Int Psychogeriatr. 2013;25(5):805-13.

41. Fabrigar LR, Petty RE, Smith SM, Crites SL, Jr. Understanding knowledge effects on attitude-behavior consistency: the role of relevance, complexity, and amount of knowledge. J Pers Soc Psychol. 2006;90(4):556-77.

42. Mitchell T, Woodward M, Hirose Y. A survey of attitudes of clinicians towards the diagnosis and treatment of mild cognitive impairment in Australia and New Zealand. Int Psychogeriatr. 2008;20(1):77-85.

43. Wang M, Xu X, Huang Y, Shao S, Chen X, Li J, et al. Knowledge, attitudes and skills of dementia care in general practice: a cross-sectional study in primary health settings in Beijing, China. BMC Fam Pract. 2020;21:89.

44. Diamantopoulos A, and Heidi M. Winklhofer Index Construction with Formative Indicators: An Alternative to Scale Development. Journal of Marketing Res. 2001;38(May):269-77.

45. Lu Y, Liu C, Wang Z, Fawkes S, Yu D. Knowledge, attitudes and practice of general practitioners towards community detection and management of mild cognitive impairment: a cross-sectional study in Shanghai, China. BMC Fam Pract. 2021.

46. Davis RE, Jacklin R, Sevdalis N, Vincent CA. Patient involvement in patient safety: what factors influence patient participation and engagement? Health Expect. 2007;10(3):259-67. 
47. World Health Organization. Monitoring the building blocks of health systems: a handbook of indicators and their measurement strategies. WHO, 2010.

48. Hogg W, Rowan M, Russell G, Geneau R, Muldoon L. Framework for primary care organizations: the importance of a structural domain. Int J Qual Health C. 2008;20(5):308-13.

49. Harris PA, Taylor R, Minor BL, Elliott V, Fernandez M, O'Neal L, et al. The REDCap consortium: Building an international community of software platform partners. J Biomed inform. 2019;95:103208.

50. Hair JF, Risher JJ, Sarstedt M, Ringle CM. When to use and how to report the results of PLS-SEM. European bus rev. 2019;31:2-24.

51. van Riel ACR, Henseler J, Kemény I, Sasovova Z. Estimating hierarchical constructs using consistent partial least squares. Ind Manage Data Syst. 2017;117(3):459-77.

52. Utomo P, Kurniasari FJI. Firm Competitiveness and Firm Performance-The Impact of Alliance Formation in Early Stage Digital Start-ups. IJICC (International Journal of Innovation, Creativity and Change). 2019;5(6):776-88.

53. Ringle CM, Wende, S., and Becker, J.-M. "SmartPLS 3." Boenningstedt: SmartPLS GmbH, http://www.smartpls.com. 2015.

54. Friedman DB, Rose ID, Anderson LA, Hunter R, Bryant LL, Wu B, et al. Beliefs and communication practices regarding cognitive functioning among consumers and primary care providers in the United States, 2009. Prev Chronic Dis. 2013;10:120249.

55. Bradford A, Kunik ME, Schulz P, Williams SP, Singh H. Missed and delayed diagnosis of dementia in primary care: prevalence and contributing factors. Alzheimer Dis Assoc Disord. 2009;23(4):306-14.

56. Lugtenberg M, Burgers JS, Besters CF, Han D, Westert GP. Perceived barriers to guideline adherence: a survey among general practitioners. BMC fam pract. 2011;12(1):1-9.

57. Lourida I, Abbott RA, Rogers M, Lang IA, Stein K, Kent B, et al. Dissemination and implementation research in dementia care: a systematic scoping review and evidence map. BMC Geriatrics. 2017;17(1):1-12.

58. Perry M, Drašković I, Lucassen P, Vernooij-Dassen M, van Achterberg T, Rikkert MO. Effects of educational interventions on primary dementia care: a systematic review. Int $\mathrm{J}$ geriatr psych. 2011;26(1):1-11.

59. Sopcak N, Aguilar C, O'Brien MA, Nykiforuk C, Aubrey-Bassler K, Cullen R, et al. Implementation of the BETTER 2 program: a qualitative study exploring barriers and facilitators of a novel way to improve chronic disease prevention and screening in primary care. Implement Sci. 2016;11(1):1-11.

60. Gawel J. Herzberg's theory of motivation and Maslow's hierarchy of needs. Washington DC: ERIC Clearinghouse on Assessment and Evaluation. 1997.

61. Matyas N, Aschenberger FK, Wagner G, Teufer B, Auer S, Gisinger C, et al. Continuing education for the prevention of mild cognitive impairment and Alzheimer's-type dementia: a systematic review and overview of systematic reviews. BMJ open.2019;9(7):e027719. 
62. Eccles MP, Hrisos S, Francis J, Kaner EF, Dickinson HO, Beyer F, et al. Do self-reported intentions predict clinicians' behaviour: a systematic review. Implement Sci. 2006;1:28.

63. Sheeran P. Intention-Behavior Relations: A Conceptual and Empirical Review. Eur rev soc psychol. 2002;12(1):1-36.

\section{Figures}

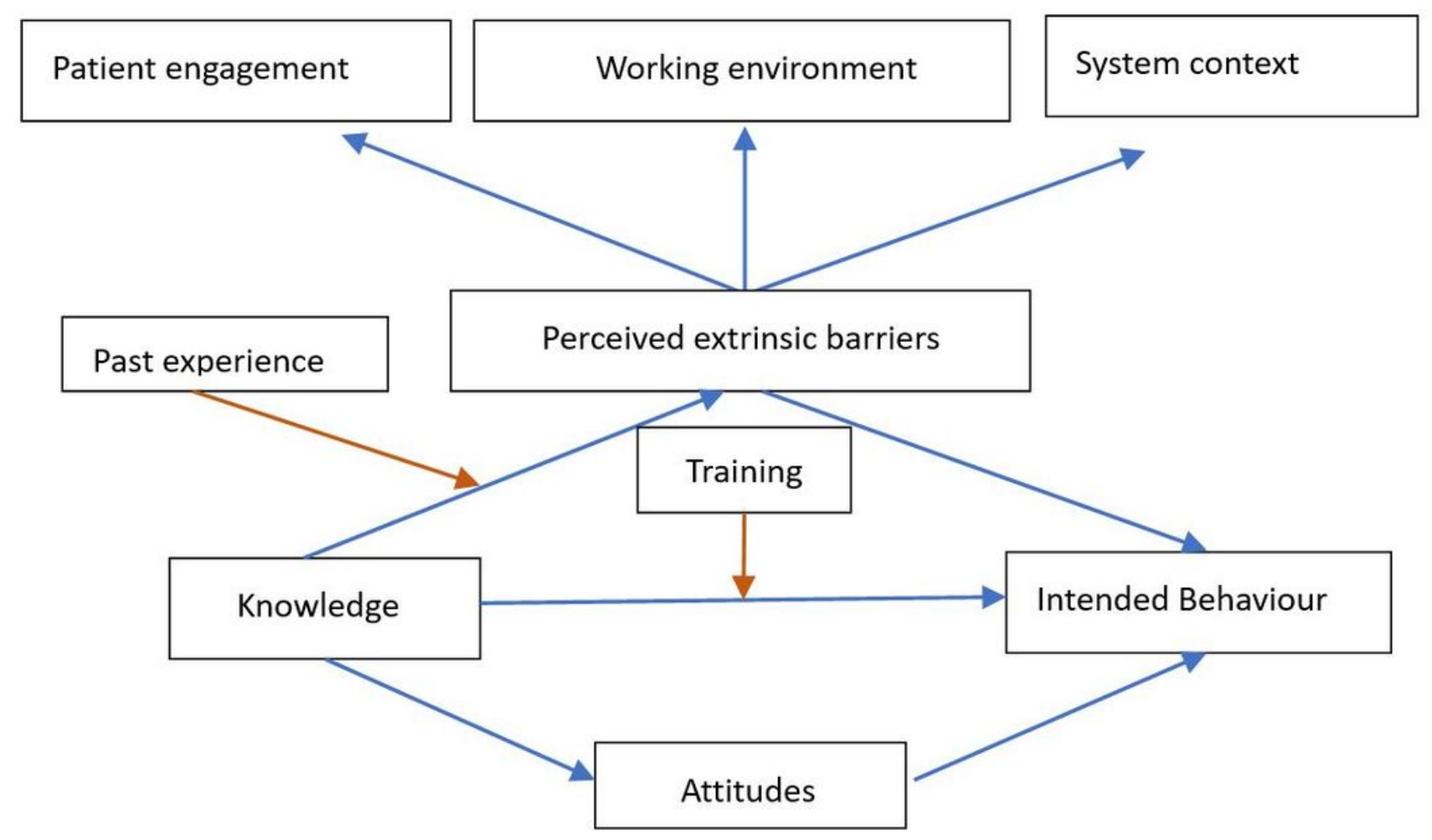

Figure 1

Structural model of intended behaviour of general practitioners in $\mathrm{MCl}$ detection and management 




Figure 2

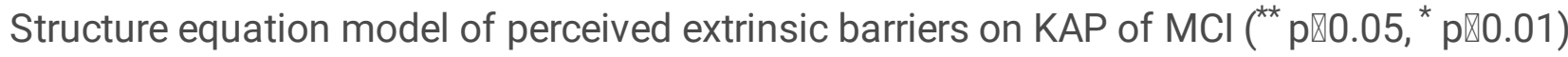






Figure 3

Moderation effect of training on the association between knowledge and intended practice

\section{Supplementary Files}

This is a list of supplementary files associated with this preprint. Click to download.

- AdditionalFile1.docx

- AdditionalFile2.docx

- AdditionalFile3.docx 